\title{
Delayed carbon policy certainty and electricity prices in Australia
}

\author{
Tim Nelson, Simon Kelley, Fiona Orton and Paul Simshauser* \\ Level 22, 101 Miller Street \\ North Sydney, NSW, 2060. \\ March 2010
}

The power industry has been grappling with regulatory uncertainty in relation to carbon since late 2004 when Australian state governments committed to the introduction of an emissions trading scheme. This article estimates the additional cost to electricity users associated with the suboptimal introduction of new power generating capacity given regulatory delays. We find the costs to be significant; under a business-as-usual electricity demand growth scenario, prices in 2020 would be about \$8.60/MWh higher than necessary. We also find that costs to consumers are lower where complementary policies are introduced to encourage energy efficiency and renewable energy.

\section{Introduction}

The climate change policy environment within Australia at the time of writing could only be described as uncertain. Since 2007, the primary policy instrument for addressing anthropogenic greenhouse gas emissions, a cap-and-trade emissions trading scheme (ETS), has wavered between bipartisan support for a 2010/11 commencement date to single party support for introduction in 2013. This wavering approach to setting public policy is having profound consequences for investors in power generating capacity given that such investments are large (i.e. between $\$ 300 \mathrm{~m}$ and $\$ 2$ billion) with particularly long useful lives (i.e. 30-50 years).

In 2004, the Labor dominated Australian States and Territories agreed to implement an ETS if the Liberal Commonwealth Government did not. The States and Territories established the National Emissions Trading Task Force, a working group of senior officials that developed a model for a cap-and-trade ETS in 2006 (NETT, 2006). By late-2006, it had become clear to industry that the Task Force should be taken seriously. In February 2007, State Premier's, through a Communiqué issued by the Council of Australian Federation confirmed this by committing to 'conclude the development phase and begin the implementation of the national emissions trading scheme' (CAF, 2007).

In December 2006, the then Prime Minister John Howard announced the establishment of a joint government-business Task Group on Emissions Trading. On 31 May 2007, the Task Group released its report to the Prime Minister recommending the adoption of a cap-and-trade ETS commencing in 2011 (PMTGET, 2007). The Prime Minister adopted many of the recommendations from the Task Group and in the event, climate change policy became a major issue during the 2007 Commonwealth election. Importantly, both major political parties committed to introducing an ETS early in the next decade. After several years of policy debate, industry had at long last been provided with relative investment certainty and could finally start to incorporate a carbon price into future investment decisions with a degree of confidence around timing. ${ }^{1}$

\footnotetext{
* Tim Nelson is Head of Economic Policy \& Sustainability, Simon Kelley is Manager of Energy Policy and Regulation, Fiona Orton is Carbon Project Analyst and Paul Simshauser is Chief Economist and Group Head of Corporate Affairs at AGL Energy Ltd. Paul Simshauser is also Professor of Finance at Griffith University. The views expressed in this paper are those of the authors and any errors or omissions remain the responsibility of the authors.

${ }^{1}$ Of course, the price of carbon remained highly uncertain. But industry, especially the power industry, has long grown accustomed to dealing with, and managing the risk of, commodity price uncertainty.
} 
In 2008 and 2009, the newly elected Rudd Commonwealth Government began the process of designing, consulting and introducing legislation for their Carbon Pollution Reduction Scheme (CPRS), a cap-and-trade ETS covering almost all of the Australian economy. Whilst initially enjoying bipartisan support from the Liberal Opposition, support evaporated in late-2009 following a change in the Opposition Leadership. The change in leadership was in fact driven by an anti-ETS sentiment within the Liberal Party. Investment certainty which was gradually emerging from the CPRS similarly began to evaporate. By any reasonable analysis, industry certainty had been wound back to the same position it had been in just prior to 2006. At the time of writing, investors in carbon intensive capital stock such as power generation are now unable to accurately plan new base load plant investments until certainty is restored with the introduction of the CPRS.

The purpose of this article is to examine wholesale electricity prices using a dynamic, partial equilibrium model of the National Electricity Market (NEM) under conditions of policy certainty and perfect competition under a uniform first price auction clearing model, which is consistent with the NEM design. Given the non-trivial impact of carbon regulatory uncertainty, investors will seek to minimise capital costs to reduce the risk of stranded assets in a period of uncertainty. Our modeling estimates the higher prices associated with this sub-optimal capital stock being introduced due to the underlying policy uncertainty.

Importantly, this article does not estimate the costs associated with a particular carbon trajectory. Instead, it assumes a binary decision for investors in meeting new and uncertain electricity demand and estimates the costs associated with deploying either Open Cycle Gas Turbine (OCGT) plant or Combined Cycle Gas Turbine (CCGT) plant. By examining the additional costs associated with regulatory uncertainty, this paper provides a minimum estimate of the costs associated with delayed ETS policy settings.

This article is structured as follows: Section 2 provides a historical outline of the development of climate change policy in Australia. Section 3 outlines the binary decision making between OCGT and CCGT plant investments to meet demand under conditions of regulatory certainty and uncertainty. In Section 4, we outline the optimal plant mix and average system cost for 2010 based upon a CY2009 electricity load duration curve for the NEM. Section 5 then produces estimates of the optimal plant mix in 2020 based upon regulatory certainty being established in 2013 (based upon the current timing for operation of the CPRS) and contrasts this with a scenario where regulatory certainty was theoretically established during 2010 as initially envisaged at the 2007 federal election. These results are then analysed in Section 6 to determine the additional costs for electricity consumers associated with delayed regulatory certainty in relation to climate change policy. Our conclusions follow.

\section{Climate change policies in Australia}

Australia has long been aware that its coal-dominated power generation sector is the largest point source of greenhouse gas (carbon dioxide equivalent - $\mathrm{CO}_{2} \mathrm{e}$ ) emissions with less than 100 sites producing more than one-third of national emissions. The policy debate on an optimal national approach to mitigate carbon emissions has been ongoing for the better part of two decades. The following provides an important historical account of the history of this debate, including the policy milestones and the measures that have been successful from a legislative perspective.

In June 1992, at the Rio Earth Summit, Australia together with 152 other countries signed the United Nations Framework Convention for Climate Change (UNFCCC). Later in that same year the Commonwealth Parliament's Senate Standing Committee on Industry, Science and Technology released the report Gas and Electricity Combining Efficiency and Greenhouse 
(Senate Standing Committee on Industry, Science and Technology, December 1992). A key recommendation of this report was that the use of natural gas in power generation should be increased in order to reduce emissions. ${ }^{2}$ This 1992 report is regarded as the commencement of government recognition that the power generation sector will require specific policy intervention to mitigate greenhouse gas emissions given Australia's resource endowments. ${ }^{3}$

Following the Senate Standing Committee report in 1992, Australia's deliberations on what would be the most appropriate mechanisms to mitigate greenhouse gas emissions went through a number of iterations. In 1997 the Inter-Governmental Committee on Ecological Sustainable Development released a discussion paper on directions for a National Greenhouse Gas Strategy. The Productivity Commission (then known as the Industry Commission) made a submission to the Committee urging further research into the use of market mechanisms, including the use of tradeable emission permits, to minimize the cost of emission reductions over the long run. ${ }^{4}$ The Productivity Commission's research noted that tradable permits between power generators could deliver a lower cost outcome than an externally determined tax rate on carbon emissions.

The Generator Efficiency Standards (GES) program was introduced on 1 July 2000. ${ }^{5}$ Using a voluntary Deed of Agreement between government and business the GES required existing power generators above $30 \mathrm{MW}$ of capacity and with output of $50 \mathrm{GWh}$ per annum or more to report their emissions performance annually. In addition to reporting, generators were obliged to implement efficiency improvements which faced costs of $\$ 10 / \mathrm{tCO}_{2} \mathrm{e}$ or less. Importantly, the GES also included performance standards for new generation plant and were set at international best practice for natural gas, black and brown coal generation plant. ${ }^{6}$

What is believed to be the world's first mandatory greenhouse gas ETS commenced in New South Wales on 1 January 2003. As the earliest example of a baseline-and-credit ETS (as distinct from a cap-and-trade), the Greenhouse Gas Reduction Scheme (GGAS) imposes a liability on electricity retailers in NSW to meet annual emission targets through the acquisition and surrender of abatement certificates (NGACs) that each represent 1 tonne $(t)$ of greenhouse gases $\left(\mathrm{CO}_{2} \mathrm{e}\right)$. Owing to NSW participation in the National Electricity Market (NEM), eligible sources of NGACs exist across all jurisdictions connected to the NEM. Targets are based on a per capita metric, and the current target is $7.27 \mathrm{tCO}_{2} \mathrm{e}$.

The point of liability under GGAS is on the electricity retailer. However, generators have an implicit carbon price incentive through the ability to create credits (NGACs) for emission reductions from individual power stations. Participation has been strong, and eligibility is not restricted to any particular fuel or technology. Around 130 generators are accredited abatement providers under GGAS ${ }^{7}$ and to date over $73 m \mathrm{mCO}_{2} \mathrm{e}$ of abatement has been achieved. ${ }^{8} \mathrm{~A}$ number of legislative amendments in recent years prepared GGAS for transition to a national ETS and in 2009 the Commonwealth Government offered a \$130m package to assist those adversely affected by the transition. GGAS is now closed to new projects and abatement targets are no longer tightening.

Prompted by the successful commencement of GGAS, and the refusal of the Commonwealth Government to consider a national ETS, the states and territories collaborated to form the National Emissions Trading Taskforce or NETT in 2004. Over the ensuing two years, the NETT set about developing the detailed policy framework of a national cap-and-trade ETS for

\footnotetext{
${ }^{2}$ http://www.aph.gov.au/library/pubs/bp/1997-98/98bp04.htm

3 Australia has very low cost coal resources relative to unit gas costs. For further details on the dilemma facing gas relative to coal in power generation, see Simshauser (2010).

${ }^{4}$ Industry Commission April 1997 http://www.pc.gov.au/ic/research/submission/icesd/mediarelease

${ }^{5}$ http://www.environment.gov.au/settlements/ges/index.html

${ }_{6}^{6}$ Annual reports under the GES were last submitted in 2008. The program has since been abandoned.

${ }^{7}$ GGAS Annual Report, July 2009.

${ }^{8}$ See GGAS Registry (June 2010) at www.ggas-registry.nsw.gov.au
} 
application to the stationary energy sector. After a number of key investigative publications, the NETT concluded in December 2007 with the release of its final report on a possible design for a national ETS. The design was influenced by the European Union ETS which had already commenced, and recommended a number of domestic offsets also be eligible.

The NETT was borne out of inaction by the Federal Government, and similarly industry and other stakeholders were also concerned by the national uncertainty, given strong progress at the state level. Two key groups assembled to address this issue. The World Wildlife Fund Australia, together with Frontier Economics and The Australian Gas Light Company (AGL) performed an economic evaluation on how to achieve emission reductions in the electricity sector. The study found that Australians could pay as little as $\$ 250$ each to achieve a $40 \%$ reduction in greenhouse gas emissions from the country's power generation industry by $2030 .{ }^{9}$ In addition, the Australian Business Roundtable on Climate Change, composed of industry and environment groups, undertook a series of investigations to conclude Australia should not delay action on climate change as early affordable steps in the near term may avoid costly actions later. ${ }^{10}$

Recognising the degree of state government and industry momentum, the Prime Minister commissioned a Task Group on Emissions Trading (TGET) in December 2006. Its report, recommending the development of a national cap-and-trade ETS, was released in May 2007, and the Prime Minister adopted this recommendation as Coalition Government policy on 4 June 2007. Given the opposing Labor Party's support for a national ETS, this was the first time that bipartisan support existed at the national level. The main point of difference at this stage was the commencement date, although the difference was only 18 months. This bi-partisan support captured 15 years of debate on the relative merits of a national ETS to mitigate greenhouse gas emissions in Australia.

Later in 2007, the National Greenhouse and Energy Reporting Act 2007 came into effect obligating all large emitters to report on greenhouse gas emissions, and the current Labor Government was elected, committing to a national ETS in 2010. The year 2007 finished with Australia ratifying the Kyoto Protocol at the UN Conference of the Parties in Bali.

The Garnaut Climate Change Review was commissioned in early-2007, as a pre-emptive action by the then Federal Labor Opposition and the Labor State and Territory Governments. With a change of federal government, the conclusions of the Garnaut Review regarding the need to end uncertainty and introduce a national ETS ${ }^{11}$ ultimately dovetailed with policy development for the CPRS in 2008.

The CPRS was introduced in a Green Paper in July 2008. It was the first detailed step by a Federal Government towards the introduction of a national ETS. The subsequent White Paper provided conclusive direction on the Government's intent to legislate a national ETS with wide coverage of the economy, and a 2020 target range of 5 to 15 per cent below Australia's CY2000 emission levels. Exemplifying the firmness of this direction, a fledgling carbon market emerged for Australian Emission Units, the tradable permits under the CPRS. This market steadily built upon the first trade of AEUs in May 2008, as power generators began to hedge in anticipated future input costs.

Legislation to enact the CPRS was introduced to Parliament in May 2009. The legislation was consistent with the White Paper, however it now featured scope to tighten the 2020 targets to 25 per cent and the commencement date had been delayed to 2011 following an extensive consultation process. This was the first attempt to legislate, but was voted down in the Upper House (i.e. the Senate) some three months after being introduced to Parliament. Negotiations

\footnotetext{
${ }_{9}^{9}$ Options for moving towards a lower emission future, December 2006. http://www.wwf.org.au/publications/lower-emission-future/

${ }^{10}$ Australian Business Roundtable 2007 - http://www.developmentgateway.com.au/

${ }^{11}$ The Garnaut Climate Change Review, Final Report, 2008.
} 
between the Government and the Liberal-National Party Coalition together with an independent Senator failed to progress. The Government shortly reintroduced the CPRS Bills in October 2009, aiming to achieve passage of the legislation before the landmark Copenhagen UN Climate Change Conference in December 2009. This second attempt to pass the CPRS was subject to intense negotiations between the Government and the Coalition Opposition. A number of key amendments were agreed to, focused on smoothing the transitional impacts to industry, including a marked increase in structural adjustment assistance to eligible coal-fired generators, and a mechanism to facilitate low emission reinvestment in the sector.

In a dramatic turn of events, the Coalition Opposition leadership changed just as bi-partisan support for the CPRS emerged. With a change of leadership came a change of policy, and the renegotiated CPRS was voted down for a second time by the Senate at the beginning of December. The legislation was introduced for a third time to Parliament in February 2010, however at the time of writing the Government has since announced a delay of legislating the CPRS until at least 2013, subject to greater public consensus domestically and progress on international action. ${ }^{12}$ For nearly two decades now, the power generation sector has been the subject of policy speculation with respect to controls on greenhouse gas emissions. Without exception, power generation has been the key sector to be subject to this policy debate, and in at least two scheme iterations, power generators have participated in measurement, reporting and efficiency improvement regimes. There is little doubt that the sector has suffered from this uncertainty, and Energy Ministers from both sides of politics have publicly acknowledged this. Serendipity based on the legacy of initial government investment in power plants has broadly carried the industry through this uncertainty, but as demand grows and capacity tightens, a decisive conclusion is increasingly needed.

\section{Binary decision for new plant: baseload gas or peaking gas}

In considering the optimal plant mix for 2020, it is necessary to first consider the options available to investors in new power generation plant designed to meet increasing electricity demand. The Australian generation mix is vastly different when considered on a capacity and output basis. In output terms, Australian power generation is dominated by coal with around $81 \%$ of all output being produced by black and brown coal generators. However, only 58\% of Australian power generation capacity is coal-fired. Table 1 contains the output and capacity across the three major generation types in the Australian electricity market.

Table 1: $\quad$ Output and Capacity of Australian Electricity Generators

\begin{tabular}{ccccc}
\hline Type & Output $(\mathrm{GWh})$ & \% of Total & Capacity (MW) & \% of Total \\
\hline Coal & 186,464 & 81 & 29,407 & 58 \\
Gas & 28,321 & 12 & 13,253 & 26 \\
Renewables & 14,970 & 7 & 8,154 & 16 \\
\hline
\end{tabular}

Source: esaa (2010)

The stark contrast between capacity and output within the Australian electricity market is due to the inability of the industry to manage variable demand through inventory management. As electricity cannot be stored economically, it must be consumed as it is produced. Accordingly, as electricity demand increases, additional generation capacity must be brought online. This results in some proportion of the capital stock being utilised for much lower periods of time than in other industries.

${ }^{12}$ Minister for Climate Change and Energy Efficiency, 28 April 2010.

http://www.climatechange.gov.au/minister/wong/2010/transcripts/April/tr20100428a.aspx 
Based upon this unique feature of electricity markets, investors in new plant capacity consider the economics of the technology being developed against a backdrop of different growth trajectories across the various demand categories. At present, growth in peak demand is outstripping growth in base or underlying energy demand. Table 2 outlines the ratio of peak demand growth to underlying growth in energy demand in the different jurisdictions in the NEM within Australia.

Table 2: $\quad$ Growth in Electricity Demand

\begin{tabular}{cccc}
\hline State & $\begin{array}{c}\text { \% Growth in Peak } \\
\text { Demand }\end{array}$ & $\begin{array}{c}\text { \% Growth in Underlying } \\
\text { Energy Demand }\end{array}$ & $\begin{array}{c}\text { Ratio of Growth } \\
\text { (\%) }\end{array}$ \\
\hline QLD & 3.6 & 3.2 & 113 \\
NSW & 2.2 & 1.5 & 147 \\
VIC & 2.2 & 1.2 & 183 \\
SA & 2 & 2 & 100 \\
\hline
\end{tabular}

Source: AEMO (2009).

Managing this economically requires market participants to invest in plant based upon characteristics matched to the relevant demand conditions. Effectively, this falls into three categories:

- Generation plant with relatively high capital costs but low operating costs is used to meet baseload demand (demand that occurs for most of the time). Historically, black and brown coal generation which is slow to start or shut down has been used to meet baseload demand and such plant typically operates at a 75-90\% annual capacity factor;

- Intermediate demand (nominally the higher 'daytime demand') is generally met by plant with medium capital and operating costs and flexible operating capacity (i.e. can be ramped up quickly). CCGT plant is generally used to meet intermediate demand and typically runs at an annual capacity factor of between $40-60 \%$; and

- Generation plant with relatively low capital costs but high operating costs is used to meet peak demand (demand that only occurs on the hottest and coldest days of the year, or during power system contingency conditions such as unexpected plant outages). OCGT plant or hydro generation (pre-existing capacity built by governments) which can be ramped up very quickly is generally used to meet peak demand and typically operate at annual capacity factors of between 5-30\%.

The economics of power generation is considered in greater detail in Section 4. At present, the LRMC of coal fired generation, CCGT and OCGT is \$50, \$58 and \$96 per MWh respectively (ACIL Tasman, 2009). In the absence of a carbon price, investors could choose to install coalfired generation to meet baseload demand because of its low overall cost. The flexibility (i.e. fast start nature) of CCGT and OCGT plant is preferred for intermediate and peak demand even though the operation of these plants has a higher LRMC than coal-fired generation.

But the economics of meeting variable demand is not the only decision faced by investors. As outlined in Section 2, climate change policy and uncertainty about long-term policy settings is a critical factor in considering what type of generation to build. Currently the average intensity of power generation in the NEM is about 0.95 tonnes of greenhouse gases per MWh. It is generally accepted that targets for limiting climate change to a $2^{\circ} \mathrm{C}$ temperature increase will require Australia's power generation fleet to operate at an intensity level of around 0.17 tonnes of greenhouse gases per MWh by $2050 .^{13}$

13 To contribute to a global target of 450ppm - Australia’s Low Pollution Future, Commonwealth Treasury, 2008, Page 174. 
It is entirely unlikely that market participants will be able to secure project finance for a Greenfield coal-fired power station because the emissions profile is quite simply inconsistent with the longer-term targets accepted by all levels of government in Australia. Best-practice coal-fired generation has an emissions intensity in the order of 0.8 tonnes per MWh of electricity generated compared to CCGT plant at 0.4 tonnes per MWh (ACIL Tasman, 2009). As such, at a practical level, even though it is the lowest cost technology available to meet baseload electricity demand, coal-fired power stations are unlikely to be built in Australia by private sector participants based upon current or projected policy settings because both the equity capital markets and project banks would find it difficult to accept the heightened risk of manifest asset stranding that would arise if and when an ETS is eventually legislated. All investors are aware that even in the absence of a carbon price today, a shadow carbon price exists and when it is eventually revealed, it will render any such investment today as unprofitable in the future.

Ironically, investors today are also unable to secure project finance for baseload and intermediate thermal alternatives to coal (e.g. CCGT) while policy settings explicitly allow coal to be built. While all reasoned logic dictates that coal would not be built under current conditions, nobody can guarantee this. So while a CCGT plant would have a substantially lower emissions intensity than coal at 0.4 tonnes per MWh, the absence of an explicit carbon price creates unacceptable risks for investors in CCGT plant as the higher cost structure of CCGT plant would be undermined should new coal plant be financed and constructed.

To illustrate this point, we have modeled a 380MW CCGT plant in QLD under a conventional project financing arrangement. This reveals that the plant would enter financial default in its first year of operations given existing wholesale electricity prices at the time of writing. Figure 1 illustrates this point.

Figure 1: Economic Returns on a Greenfield 380MW CCGT Plant in QLD

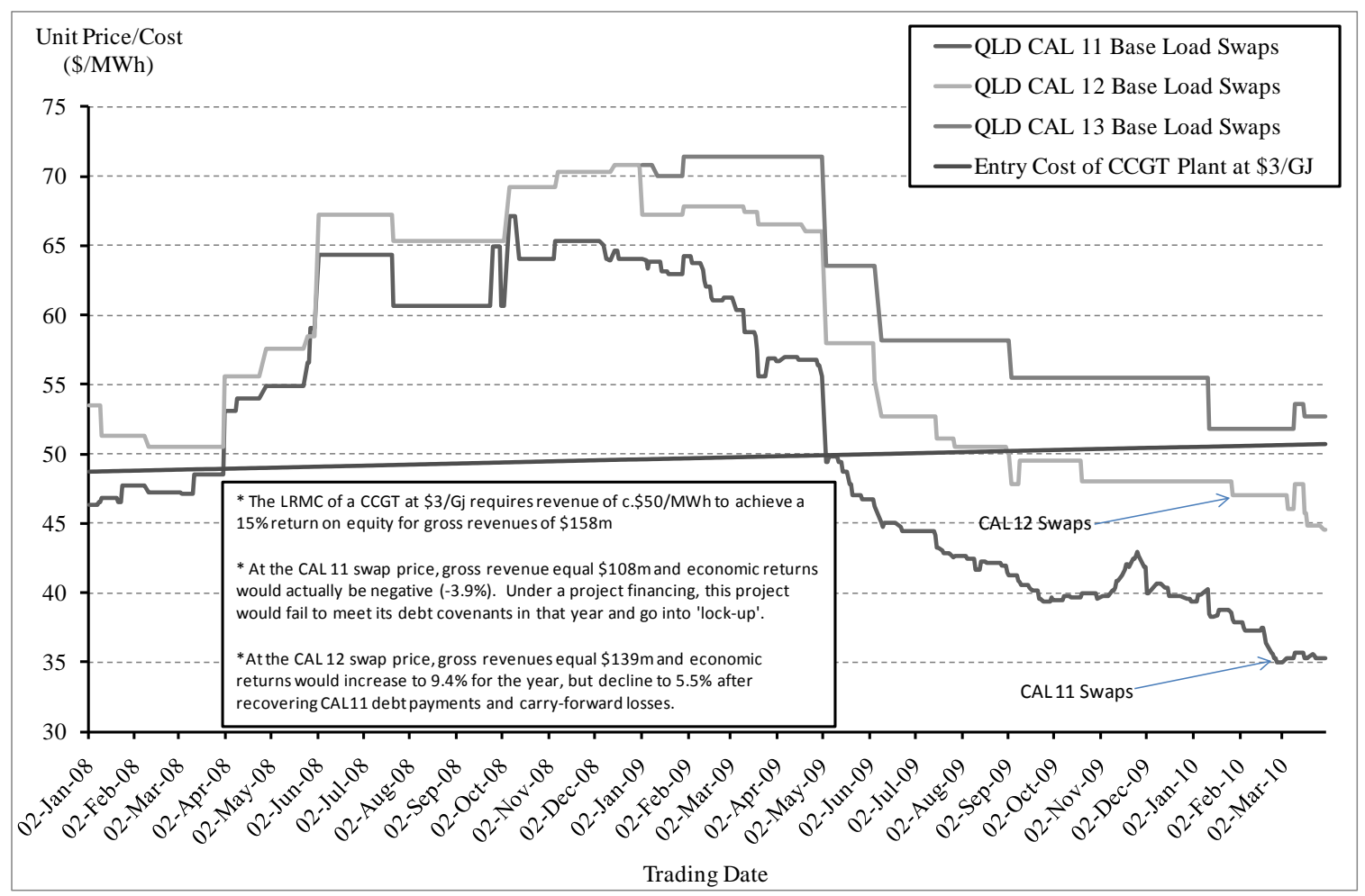

Figure 1 demonstrates that wholesale electricity swap prices (CAL 11 and CAL12 Base Load Swaps) are significantly below the entry cost of a CCGT plant which is based upon an input fuel price of \$3/GJ and no carbon price. However, at any time between between March 2008 and May 
2009, forward electricity swap prices were high enough to justify investment in a new CCGT. This is not a coincidence. In fact, it demonstrates our key thematic. The only time at which prices could justify commitment to a new CCGT was between the beginning of 2008 and May 2009, the exact timeframe where investors had confidence in bi-partisan support for emissions trading being developed within Australia.

Without mandatory performance standards that reflect the long-term emission reductions required or a broad-based ETS with long term targets, 'investment paralysis' is entirely predictable. This effectively leaves investors with one option for investment to ensure security of supply, OCGT plant, because it minimises 'capital at risk'. In summary, the options facing investors under scenarios of regulatory certainty and regulatory uncertainty are summarised in Table 3.

Table 3: $\quad$ Scenario Options for Investment in New Power Plant Capacity

\begin{tabular}{cccc}
\hline Scenario & Baseload & Intermediate & Peaking \\
\hline Regulatory Certainty & CCGT & CCGT & OCGT \\
Regulatory Uncertainty & None & OCGT & OCGT \\
\hline
\end{tabular}

The short to intermediate-run consequences of this situation are dire for the power industry. Until certainty is provided, investors will seek to minimise capital costs (and therefore the risk of asset stranding) by investing in OCGT to maintain security of supply. As noted in Simshauser, Molyneux and Shepherd (2010), the capital costs of CCGT and coal generation are 1.5 and 2.6 times greater than the capital costs of OCGT. The prudent action to minimise the risk of stranded assets is to install OCGT rather than CCGT irrespective of the demand profile, given regulatory uncertainty around carbon policy. For so long as uncertainty remains a feature of the policy environment facing power generators, OCGT will be sub-optimally used to meet growth in energy demand, resulting in lower capital cost exposure for investors, but higher prices and carbon emissions for end consumers.

\section{Optimal plant mix in 2010}

In assessing the optimal plant mix in 2010, we have used cost assumptions derived from ACIL Tasman (2009). Rather than adjusting costs over time to reflect changes in input fuel prices and capital costs, we have kept constant the long-run marginal (LRMC) cost of all plant. The purpose of this restriction on cost variability is to demonstrate that even with constant prices and all other things being equal (such as the marginal efficiency of capital deployed), there is a significant cost associated with policy uncertainty. The LRMC of the three technologies discussed in the previous section are outlined in Figure 2. 
Figure 2: LRMC of Thermal Technologies

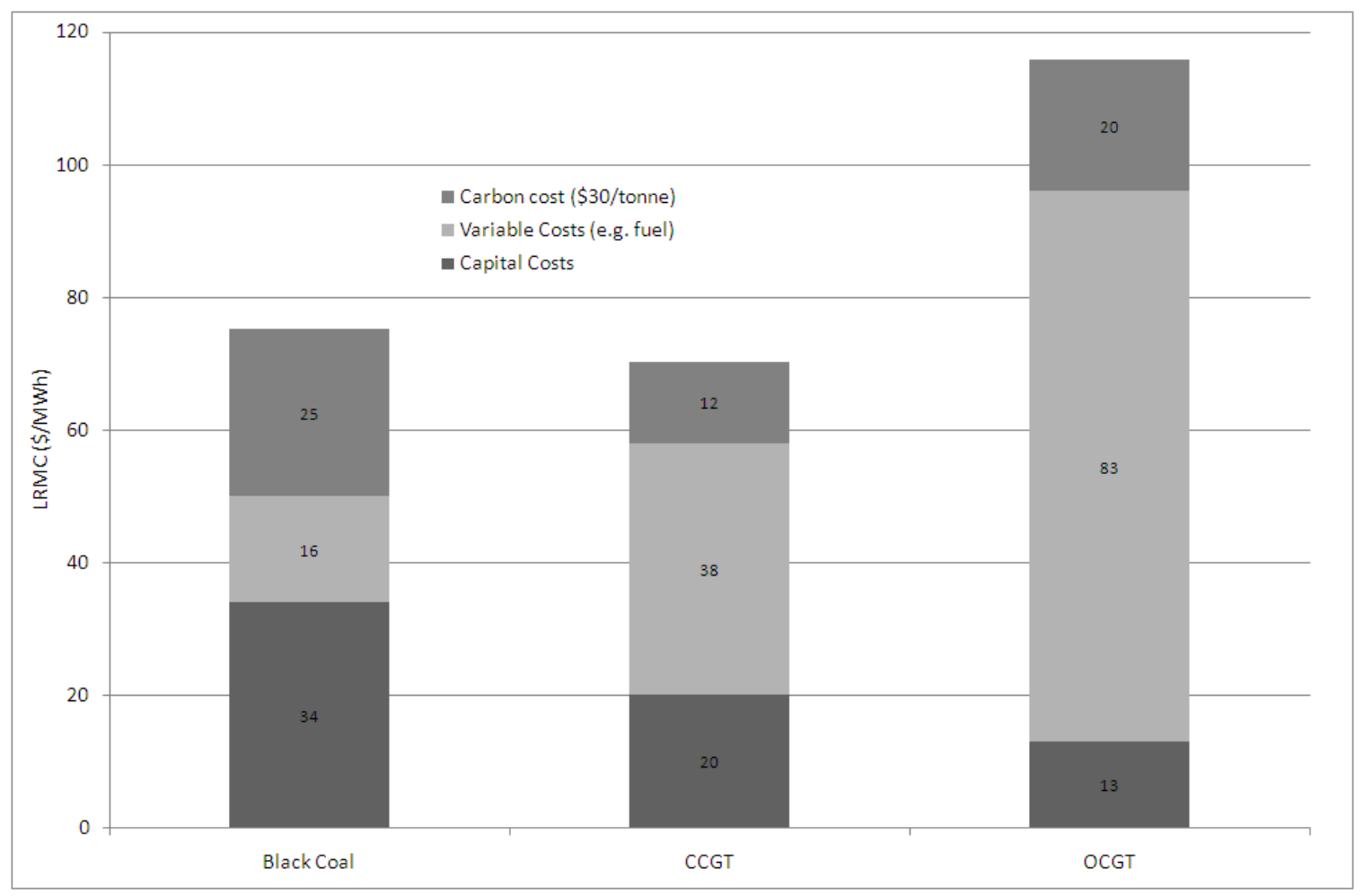

Source: ACIL Tasman (2009)

Figure 2 highlights that the proportion of capital and variable costs for the three technologies varies substantially. While the underlying LRMC of black coal generation (ex-carbon) is lowest at about $\$ 50 / \mathrm{MWh}$, capital costs represent $68 \%$ of the cost structure when operating at full load. The underlying LRMC of CCGT plant is higher at \$58/MWh, with variable costs representing $66 \%$ of the cost structure at full load. OCGT has a substantially higher underlying LRMC at \$96/MWh with the vast majority of costs (86\%) being variable, although to be sure, investment in such plant is generally biased towards peaking operation as distinct from base load operations. As outlined in the previous section, the blend of fixed and variable costs has significant implications for the optimal technology mix, a characteristic which was noted long ago by Boiteux (1949), Berrie (1967), Turvey (1968), and Crew and Kleindorfer (1975). ${ }^{14,15}$ In establishing a national load duration curve for the NEM, we have aggregated existing State-based loads. Based upon the cost structure of the technologies outlined above and the shape of the load duration curve, we are able to determine the optimal mix of generation. This is demonstrated graphically using Berrie's (1967) static partial equilibrium model, in Figure 3.

\footnotetext{
${ }^{14}$ Joskow (1975) noted that these theoretical models regarding the optimal pricing of non-storable commodities with periodic demand can generally be divided into three analytical approaches. (1) The American Approach focuses on peak prices being set at marginal running costs plus marginal capacity costs with a focus on shifting peak loads (Crew and Kleindorfer, 1975). (2) The British Approach has a heavy focus on specifying the optimal mix of supply-side technologies (Berrie, 1967; Turvey, 1968). (3) The French Approach is fundamentally a combination of both the American and British Approaches where peak demand can be shifted and supplied by an optimal mix of different technologies (Boiteux, 1949).

${ }^{15}$ See also Stoft (2002) or Simshauser (2006) amongst others for applied examples in the context of thermal power systems.
} 
Figure 3: Optimal Plant Mix in 2010

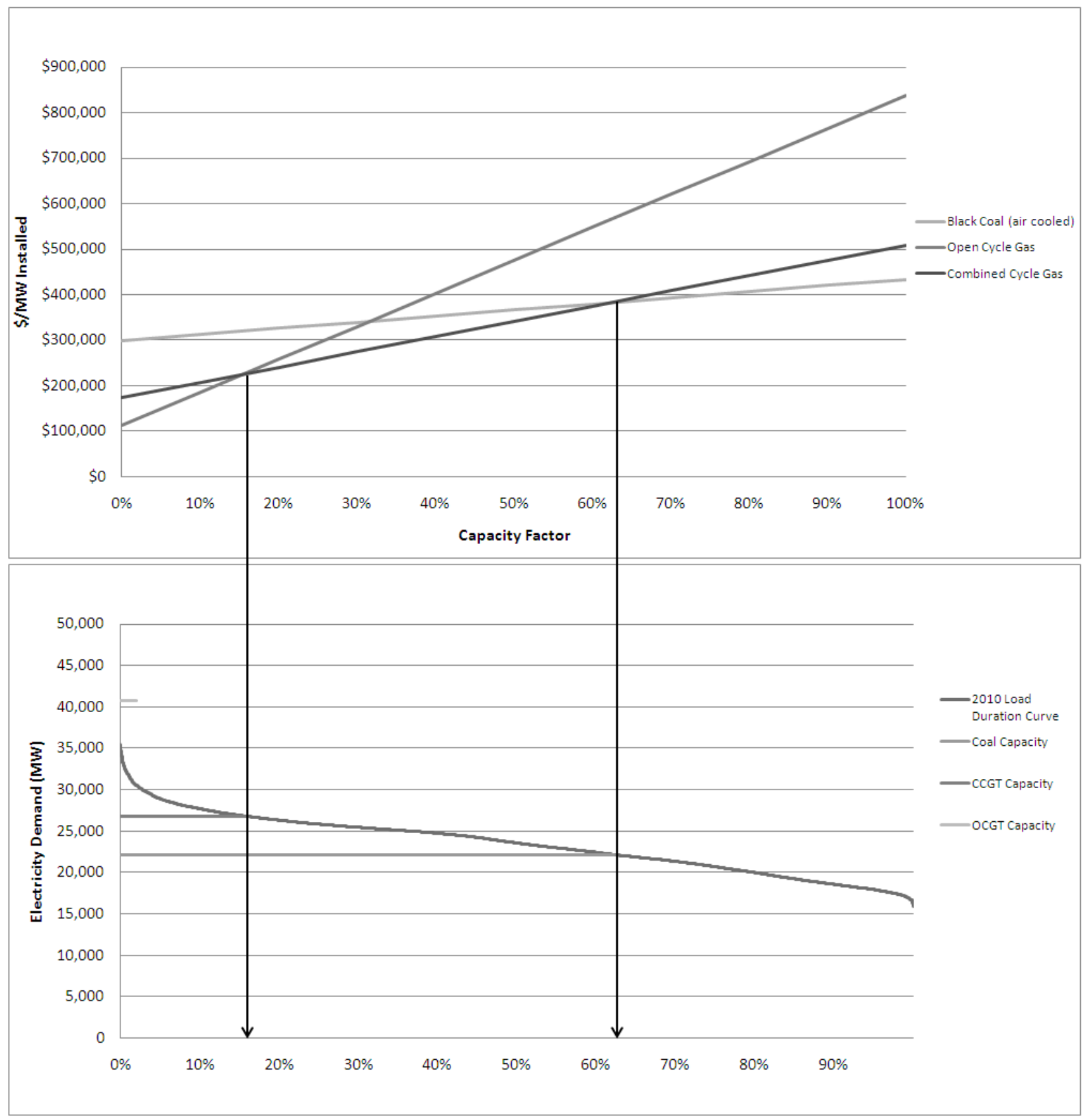


Based upon this analysis, we have determined that the optimal mix of generation for the aggregated 2010 load duration (electricity demand ${ }^{16}$ ) curve would be about 22,100 MW of black coal, 4,700 MW of CCGT and 14,000 MW of OCGT plant. This analysis is based upon a 15\% reserve margin included for security of supply purposes, which is consistent with international reserve margin benchmarks. With this capacity in place, average system cost equates to $\$ 62.57 / \mathrm{MWh}$.

\section{Optimal 2020 plant mix in Australia with and without regulatory certainty}

We have made two primary assumptions in relation to the impacts of uncertainty on investment decision making:

- A carbon scheme commences in 2013 as per the current Commonwealth Government policy; and

- Investors face a five-year delay in plant being available. This represents a reasonable estimate of the timeframe required to develop a new CCGT plant given planning, permitting and construction timeframes.

To contrast the optimal plant mix in 2020 under conditions of regulatory certainty and regulatory uncertainty, we have developed two optimal plant combinations. In the first combination, regulatory certainty is presumed from 2010 with commitments able to be made immediately to construct new CCGT plant to meet increased intermediate and baseload demand. We have called this scenario "Immediate Certainty". In the second combination, regulatory certainty is not provided until 2013 with all new demand until 2017 met by new OCGT generation. Beyond 2017, CCGT is able to be installed to meet new intermediate and baseload demand. We have called this scenario "Delayed Certainty".

Load duration curves were developed for 2017 and 2020 to determine the optimal plant mix under each of these scenarios. For each scenario, two different load duration curves were developed. The first assumes that the average annual growth in electricity demand seen in the NEM states over the period between 2000 to 2009 will continue through to 2020. Average annual demand growth for each decile of the load duration curve was calculated, and applied to predict demand for each half-hour of the load curve in 2017 and 2020. In summary, this assumes growth in electricity demand of approximately $1.5 \%$ per annum, with the increases occurring primarily during peak and high demand periods. We have called this demand scenario "BAU" or business-as-usual.

The second set of load duration curves developed for 2017 and 2020 assumes that BAU will be curbed by the widespread implementation of energy efficiency schemes, smart meters and timeof-use charging throughout the NEM states between now and 2020. We have called this demand scenario "EE" or energy efficiency. EE assumes that the implementation of energy efficiency schemes will reduce annual energy consumption by 4\% (compared to BAU), with savings occurring uniformly across the load duration curve. This case assumes that by 2020 there will be energy efficiency targets in place throughout the NEM similar to those of the New South Wales Energy Savings Scheme (ESS), which for the period of 2014 to 2020 has a reduction target of 4\% of annual NSW electricity sales. EE also assumes that there will be a broad introduction of smart meters and dynamic tariffs, and a moderate adoption of enabling ("smart") technologies. In their study of the benefits of introducing dynamic tariffs in Europe, Faruqui, Harris and Hledik (2009) estimated that under these market conditions there could be an overall residential peak demand reduction of $10 \%$. EE assumes slower growth in system-wide electricity demand (1.1\% per

${ }^{16}$ A load duration curve plots MW of demand for each half hour of the year in descending order. 
annum), with growth spread more evenly across the load duration curve, compared to the BAU case. The results of our analysis for the BAU load growth scenario are presented in Table 4 and presented graphically in Appendix 1.

Table 4: $\quad$ Optimal Plant Mix - BAU

\begin{tabular}{ccccc}
\hline $\begin{array}{c}\text { Immediate } \\
\text { Certainty }\end{array}$ & Coal & CCGT & OCGT & $\begin{array}{c}\text { Installed Capacity } \\
\text { (MW) }\end{array}$ \\
\hline 2010 & 22,100 & 4,700 & 13,900 & 40,700 \\
2017 & 22,100 & 8,500 & 17,100 & 47,700 \\
2020 & 22,100 & 10,100 & 18,400 & 50,700 \\
Delayed & & & & Installed Capacity \\
Certainty & Coal & CCGT & OCGT & (MW) \\
\hline 2010 & 22,100 & 4,700 & 13,900 & 40,700 \\
2017 & 22,100 & 4,700 & 20,900 & 47,700 \\
2020 & 22,100 & 7,600 & 20,900 & 50,700 \\
\hline
\end{tabular}

Table 4 shows that by 2017, an additional 7,000 MW of capacity is required to meet demand using our optimal plant mix model. However, there is a substantial difference between the Delayed Certainty and Immediate Certainty scenarios. The difference in timing for the provision of regulatory certainty significantly skews the distribution of optimal plant to meet demand. By 2017, there is 3,800 MW less CCGT and more OCGT in the Delayed Certainty scenario relative to the Immediate Certainty scenario. The other stark conclusion is that even with three years to correct this imbalance, the $2020 \mathrm{mix}$ is still 2,500 MW overweight OCGT and underweight CCGT. This has profound consequences for electricity prices which will be discussed in the following section.

The results of our analysis for the EE scenarios are outlined in Table 5 and presented graphically in Appendix 2:

Table 5: $\quad$ Optimal Plant Mix - EE

\begin{tabular}{ccccc}
\hline $\begin{array}{c}\text { Immediate } \\
\text { Certainty }\end{array}$ & Coal & CCGT & OCGT & $\begin{array}{c}\text { Total installed } \\
\text { Capacity (MW) }\end{array}$ \\
\hline 2010 & 22,100 & 4,700 & 13,900 & 40,700 \\
2017 & 22,100 & 6,200 & 12,700 & 41,000 \\
2020 & 22,100 & 7,700 & 13,800 & 43,600 \\
Delayed & & & & Total installed \\
Certainty & Coal & CCGT & OCGT & Capacity (MW) \\
\hline 2010 & 22,100 & 4,700 & 13,900 & 40,700 \\
2017 & 22,100 & 4,700 & 14,200 & 41,000 \\
2020 & 22,100 & 7,200 & 14,200 & 43,500 \\
\hline
\end{tabular}

The results of the EE scenarios outlined in Table 5 are similar to those discussed previously in relation to the BAU scenario but with one important difference. The magnitude of the suboptimal investment in 2017 and 2020 is significantly lower than in the BAU case. By 2017, the total installed capacity in the EE scenarios is 6,700 MW lower than in the BAU scenario and by 2020 it is 7,100 MW lower. By reducing the growth in energy demand and in particular, peak demand, we have effectively reduced the amount of extra capacity required to meet demand. Accordingly, the results are less skewed when considered by plant type. By 2017, there is 1,500 
MW less CCGT and more OCGT in the Delayed Certainty scenario relative to the Immediate Certainty scenario. This should be contrasted with the BAU case discussed previously where the corresponding figure was 2,300 MW higher at 3,800 MW. Similarly, by 2020, with three years to correct some of the suboptimal investment, there is still 500 MW more OCGT and less CCGT than in the optimal case.

There are two primary conclusions we can draw from this analysis:

- Delayed regulatory certainty on carbon skews the optimal plant mix materially even if uncertainty exists for three years. In our BAU analysis, 3,800 MW of plant has been constructed by 2017 using a sub-optimal technology. This has significant implications for price which will be discussed in the following section.

- Energy efficiency can have a material impact (assuming the regulatory drivers are known immediately) on reducing this sub-optimal plant mix result. Our EE analysis shows that by 2020, the sub-optimal investment is likely to be reduced to less than 500MW.

\section{Implications for the price of electricity}

There are significant implications for electricity prices associated with delays in the carbon regulatory framework by government. However, our analysis uses a theoretical cost model for 2010 and 2020 to determine the impact on prices, exclusive of a carbon price uplift. While the difference between the Delayed Certainty and Immediate Certainty scenarios is likely to be representative and can be used to draw conclusions about the cost of uncertainty, the actual prices in 2010 and 2020 are likely to be different from that calculated in this analysis. This is due to the fact that the plant stock in place today is not optimal from a cost perspective using only three technologies. In fact, a significant proportion of existing capacity within the NEM is hydro and other forms of generation technology not included in our analysis. ${ }^{17}$ Importantly, all of the prices presented below are "carbon exclusive" - we have not made any assumptions in relation to what carbon price may prevail.

We have used an LRMC model with a single-shot uniform first-price auction clearing mechanism to determine an average electricity price under the two scenarios. The results for 2020 are presented in Table 6.

Table 6: $\quad$ Implied Price of Optimal Plant Mix in 2020 in constant 2010 dollars

\begin{tabular}{ccc}
\hline Scenario & $\begin{array}{c}\text { BAU } \\
(\$ / M W h)\end{array}$ & $\begin{array}{c}\text { EE } \\
(\$ / M W h)\end{array}$ \\
\hline Immediate Certainty & $\$ 64.49$ & $\$ 63.75$ \\
Delayed Certainty & $\$ 73.09$ & $\$ 67.72$ \\
\hline
\end{tabular}

It is clear from Table 6 that any delay in the provision of certainty has material implications for any price forecast associated with the plant mix in 2020. Recall from Section 4 that the LRMC of the 2010 system load was determined to be $\$ 62.57 / \mathrm{MWh}$. In the BAU scenario, the implied price rises from $\$ 62.57 / \mathrm{MWh}$ in 2010 to $\$ 64.49 / \mathrm{MWh}$ in 2020 in the Immediate Certainty scenario.

\footnotetext{
${ }^{17}$ Although as the NEM uses a uniform first-price auction clearing mechanism, prices should theoretically rise to the entry costs of the technologies used in the analysis 
This increase is due to the load duration curve becoming 'peakier' (i.e. peak demand is growing faster than underlying demand). However, the Delayed Certainty scenario shows that the delay in provision of regulatory certainty, which in turn results in a sub-optimal capital stock being deployed, results in a much higher underlying price of $\$ 73.09$. This is an increase of $\$ 8.60 / \mathrm{MWh}$ or $13 \%$ relative to the Immediate Certainty scenario.

However, the introduction of energy efficiency in the EE scenario has a significant impact on the price structure in 2020 . In this scenario, the implied prices is moderated to only $\$ 63.75 / \mathrm{MWh}$ in 2020 with the provision of immediate regulatory certainty, a reduction in increase of about one third relative to the BAU scenario. With less energy growth, and peak demand growth in particular, the price structure is less impacted relative to the BAU scenario. This has important implications for the price structure in the Delayed Certainty scenario. With EE measures in place, delaying the provision of regulatory certainty increases the implied price in 2020 from $\$ 63.75 / \mathrm{MWh}$ to $\$ 67.72 / \mathrm{MWh}$, an increase of $\$ 3.97 / \mathrm{MWh}$ or only $6 \%$.

There are a number of important policy implications that arise from this analysis:

- Delaying the introduction of a robust carbon policy has material implications for electricity price. Delayed introduction of a robust carbon policy for the electricity sector could see household electricity prices increase by between \$3.97/MWh and \$8.60/MWh. Based upon a final FY08 residential tariff of around \$140/MWh (Simshauser, Nelson and Doan, 2010 at p. 5), this implies increases of around 3\% to 6\% in the price of electricity for an average household. ${ }^{18}$

- The marginal increase in price is mostly a "deadweight loss". There is no benefit at all to consumers, new producers or governments. Price rises are the result of a sub-optimal capital stock being deployed to maintain system security in the absence of a carbon regime that provides investors with regulatory certainty to make optimal investment decisions. The increase in prices would occur irrespective of whether a carbon regime is or is not introduced in 2013. They are the costs of uncertainty. The only way they could be avoided is for bipartisan agreement to be reached on climate policy with immediate announcement. This would allow investors to make decisions today to optimise investment, thereby avoiding the costs associated with the introduction of a sub-optimal capital stock.

- Complementary policies can reduce, but not eliminate, the costs associated with higher electricity prices. This study has shown that the additional costs could be halved if complementary energy efficiency polices are introduced which reduce the need for new investment in generation. It is likely that the same would be true for the expanded 20\% Renewable Energy Target established in August 2009 and refined in June 2010. This could be an area for further research.

\section{Conclusion}

This study has analysed the unit cost of the plant stock required to satisfy demand in 2010, 2017 and 2020 under conditions of policy certainty, and delayed policy certainty. The results indicated that there are likely to be material cost increases and higher electricity prices from a lack of regulatory certainty around climate change policy. Unfortunately, at the time of writing the climate change policy environment within Australia could be described as uncertain at best. Since 2007, the primary policy instrument for addressing anthropogenic greenhouse gas emissions, a cap-and-trade ETS, has wavered between bipartisan support for a 2010/11 commencement date to

\footnotetext{
${ }^{18}$ Based upon average household consumption of $7000 \mathrm{kWh}$ per year.
} 
single party support for introduction in 2013. This wavering approach to setting public policy is having profound consequences for investors in long-lived power generation assets.

Our analysis indicates that the increase in electricity prices at the residential level is likely to be between $3 \%$ and $6 \%$ depending upon the demand growth scenario used. These price increases are primarily a "deadweight loss" to the economy associated with the introduction of a sub-optimal capital stock designed to minimise capital costs in an environment of carbon policy uncertainty. It is critical that policy makers note this dilemma and move quickly towards establishing a carbon policy framework that is accepted by all sides of politics. If this does not occur, these price increases are likely to be experienced irrespective of whether a broad based climate change policy is introduced or not. It is also critical that policy makers focus on complementary policies such as energy efficiency schemes and mandated renewable energy schemes to reduce the magnitude of any increase in prices associated with carbon policy uncertainty.

\section{References}

AEMO: Australian Energy Market Operator, (2009), “Electricity Statement of Opportunities”, AEMO Publication, Melbourne. Available at http://www.aemo.com.au/planning. Accessed 15 February 2010.

ACIL Tasman, April 2009, Fuel resource, new entry and generation costs in the NEM: Prepared for the Inter-Regional Planning Committee. Available from http://www.aemo.com.au/planning. Accessed 15 February 2010.

Berrie, T. (1967), “The economics of system planning in bulk electricity supply”, Electrical Review, 22(2): 425-428.

Boiteux, M. (1949), "La tarification des demandes en pointe: Application de la theorie de la vente au cout marginal”, Revue Generale de l'Electricite, Translated by H. Izzard in Journal of Business, Boiteux, M. 1960, 'Peak load pricing', Journal of Business, 33(2): 157-80.

Carew, M. And Kleindorfer, P. (1976), “Peak load pricing with a diverse technology”, Bell Journal of Economics, 7(1): 207- 231.

Commonwealth Treasury, 2008, Australia's Low Carbon Pollution Future

CAF: Council for the Australian Federation, 9 February 2007, Communiqué.

esaa: Energy Supply Association of Australia, (2010), ElectricityGas Australia, ESAA Publication, Melbourne.

Faruqui, A.,Harris, D., and Hledik, R. (2009) "Unlocking the $€ 53$ billion savings from Smart Meters in the EU”, The Brattle Group, San Francisco. Available from ahmad.faruqui@brattle.com

Faruqui, A., Hledik, R. and Sergici, S. (2009), “Piloting the smart grid”, The Electricity Journal, 22(7): 55-69.

Faruqui, A., Sergici, S. and Sharif, A. (2009), “The impact of information feedback on energy consumption - a survey of the experimental evidence”, mimeo, The Brattle Group, San Francisco. Available from ahmad.faruqui@brattle.com 
Joskow, P. (1975), “Contributions to the theory of marginal cost pricing”, Bell Journal of Economics, 7(1): 197-206.

NETT: National Emissions Trading Taskforce, 2006, Possible Design for a National Greenhouse Gas Emissions Trading Scheme.

PMTGET: Prime Ministerial Task Group on Emissions Trading, 2007, Report of the Task Group on Emissions Trading

Simshauser, P. (2006), "The emergence of structural faults on the supply side in energy only markets”, Australian Economic Review, 39(2): 130-146.

Simshauser, P. (2010), “, “Capital adequacy, ETS and investment uncertainty in the Australian power market”, Electricity Journal, Vol. 23, No. 1, pp 67-84.

Simshauser, P., Molyneux, E. and Shepherd, M. (2010), "The entry cost shock and the re-rating of power prices in New South Wales”, Australian Economic Review, Vol. 43, No.2, pp 114-135.

Simshauser, P., Nelson, T. and Doan, T. (2010), “The Boomerang Paradox: how a nation's wealth creates fuel poverty - and how to defuse the cycle”, AGL Applied Economic and Policy Research Working Paper No.17, Sydney. Available from tanelson@agl.com.au

Turvey, R. “Peak-load pricing”, Journal of Political Economy, 76(1):101-113. 


\section{Appendix 1: BAU Demand - Graphical Representation of Sub-Optimal Capital Stock}

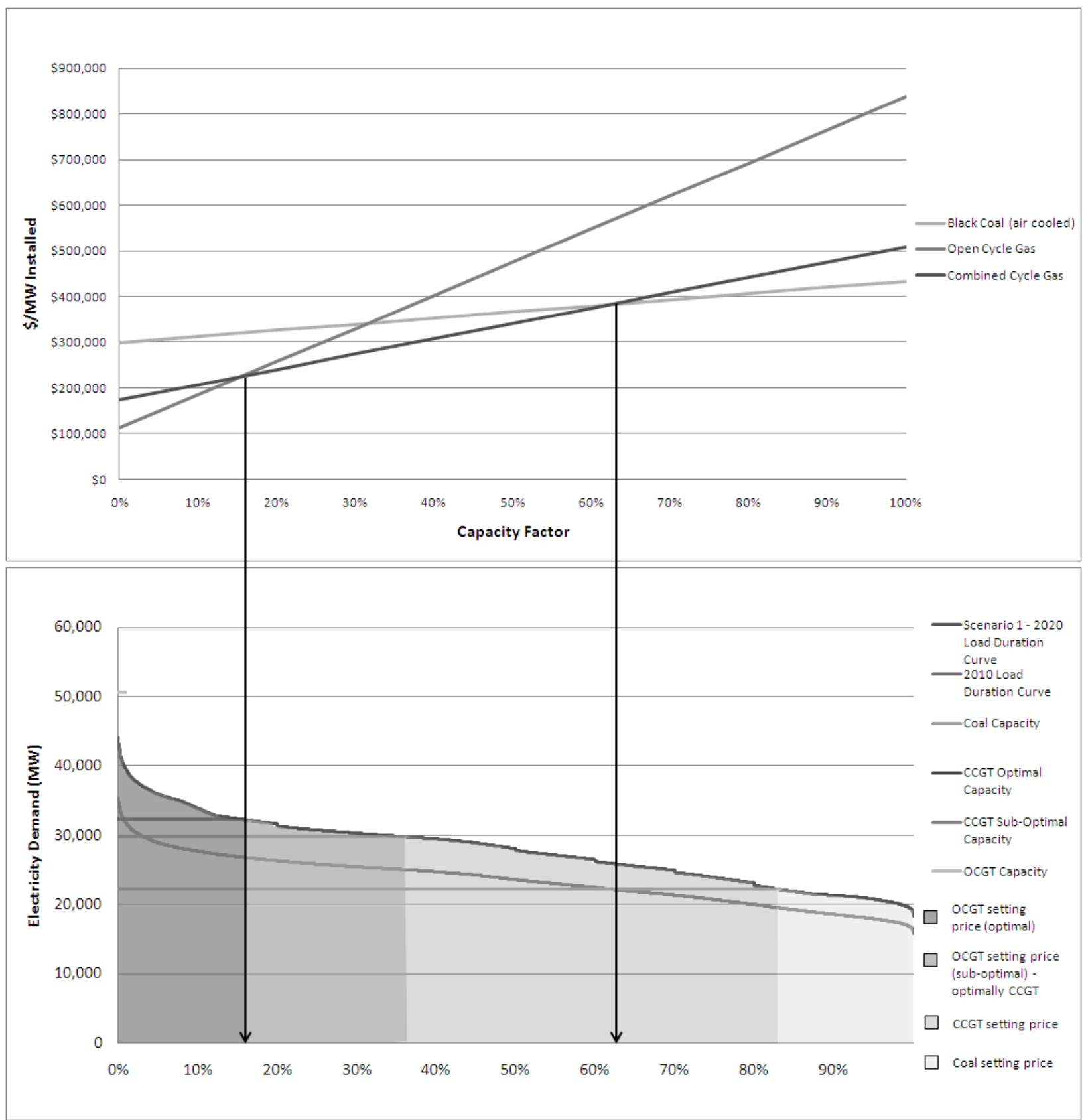




\section{Appendix 2: EE Demand - Graphical Representation of Sub-Optimal Capital Stock}

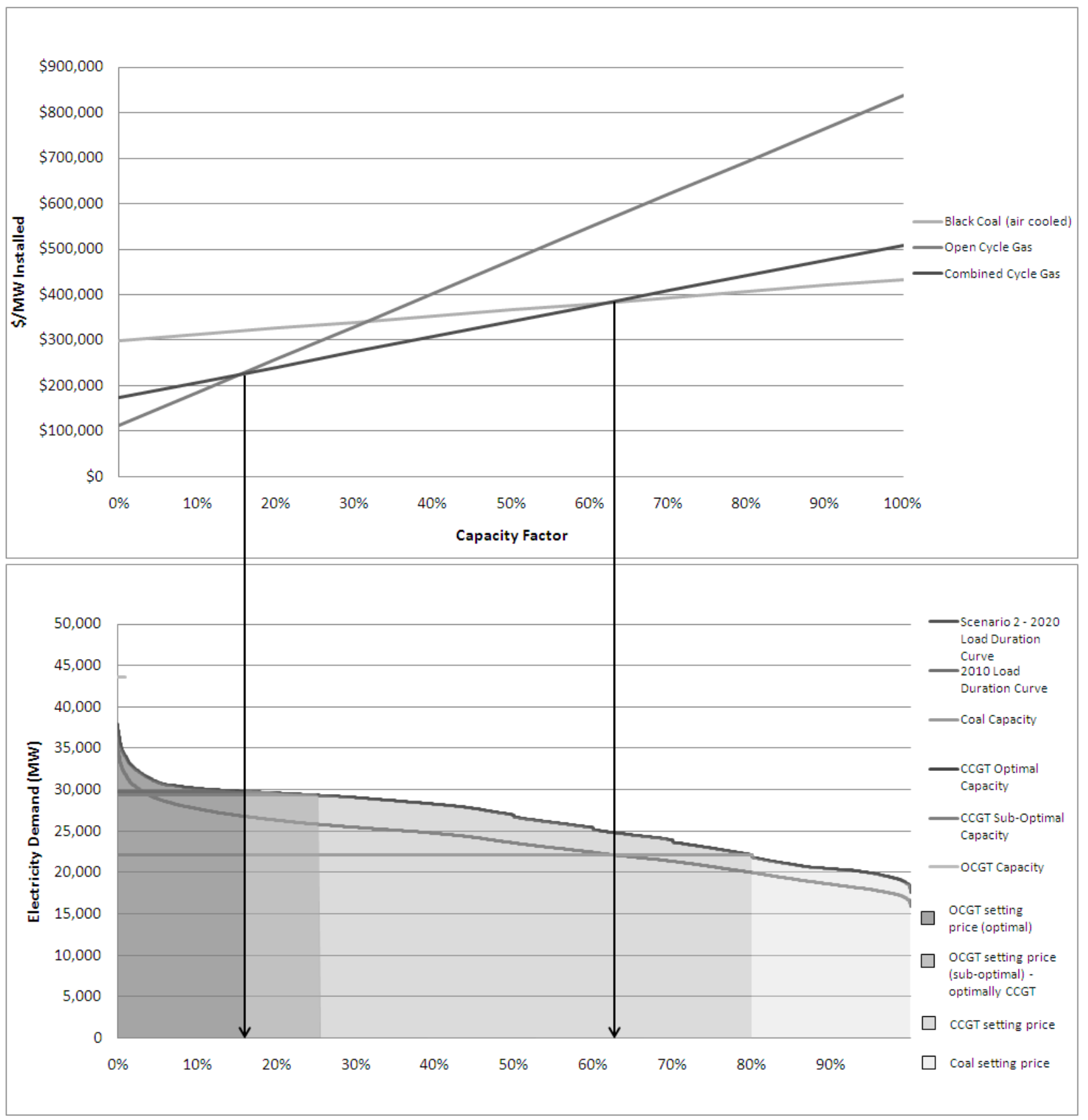

